\title{
Elevated Serum CA-125 Tumor Antigen
}

National Cancer Institute

\section{Source}

National Cancer Institute. Elevated Serum CA-125 Tumor Antigen. NCI Thesaurus. Code C142104.

A finding indicating elevated concentrations of the tumor antigen CA-125 in a blood serum sample. 